\title{
Does C5 or C6 Radiculopathy Affect the Signal Intensity of the Brachial Plexus on Magnetic Resonance Neurography?
}

\author{
Tae Gyu Seo, MD ${ }^{1}$ Du Hwan Kim, MD ${ }^{1,2,3}$, In-Soo Kim, MD, PhD ${ }^{4}$, Eun Seok Son, MD, PhD 5 \\ ${ }^{1}$ Department of Rehabilitation Medicine, ${ }^{2}$ Pain Research Center, and ${ }^{3}$ Institute for Medical Science, \\ Keimyung University School of Medicine, Daegu; Departments of ${ }^{4}$ Neurosurgery and ${ }^{5}$ Orthopedic Surgery, \\ Keimyung University School of Medicine, Daegu, Korea
}

Patients with C5 or C6 radiculopathy complain of shoulder area pain or shoulder girdle weakness. Typical idiopathic neuralgic amyotrophy (INA) is also characterized by severe shoulder pain, followed by paresis of shoulder girdle muscles. Recent studies have demonstrated that magnetic resonance neurography (MRN) of the brachial plexus and magnetic resonance imaging (MRI) of the shoulder in patients with INA show high signal intensity (HSI) or thickening of the brachial plexus and changes in intramuscular denervation of the shoulder girdle. We evaluated the value of brachial plexus MRN and shoulder MRI in four patients with typical C5 or C6 radiculopathy. HSI of the brachial plexus was noted in all patients and intramuscular changes were observed in two patients who had symptoms over 4 weeks. Our results suggest that HSI or thickening of the brachial plexus and changes in intramuscular denervation of the shoulder girdle on MRN and MRI may not be specific for INA.

Keywords Cervical radiculopathy, Magnetic resonance imaging

\section{INTRODUCTION}

Cervical radiculopathy (CR) is a common pain syndrome characterized by sensorimotor deficits due to cervical nerve root compression and inflammation [1]. In $\mathrm{C} 5$ or $\mathrm{C} 6$ radiculopathy, the proximal shoulder girdle muscles are commonly involved and it may be difficult

Received July 13, 2015; Accepted August 4, 2015

Corresponding author: Du Hwan Kim

Department of Rehabilitation Medicine, Keimyung University School of Medicine, 56 Dalseong-ro, Jung-gu, Daegu 41931, Korea

Tel: +82-53-250-7477, Fax: +82-53-250-7205, E-mail: ri-pheonix@hanmail.net

(c) This is an open-access article distributed under the terms of the Creative Commons Attribution Non-Commercial License (http://creativecommons. org/licenses/by-nc/4.0) which permits unrestricted noncommercial use, distribution, and reproduction in any medium, provided the original work is properly cited.

Copyright $\odot 2016$ by Korean Academy of Rehabilitation Medicine for the patients to raise their shoulder [1]. The diagnosis of CR is based on clinical findings, imaging studies, and electrodiagnostic testing.

There are some disorders that mimic $\mathrm{C} 5$ or $\mathrm{C} 6$ radiculopathy. Idiopathic neuralgic amyotrophy (INA) is typically characterized by severe pain in the shoulder girdle and subsequent weakness of shoulder girdle muscles [2]. Thus, it is very difficult to distinguish C5 or C6 radiculopathy from INA because of similar manifestations. Previous reports suggested that the findings such as thickening and hyperintensity of the brachial plexus on magnetic resonance neurography (MRN) may help in early diagnosis of INA $[3,4]$.

However, we hypothesized that previous MRN findings suggestive of INA could also be present in C5 or C6 radiculopathy patients because nerve root enhancement and 
thickening on contrast-enhanced magnetic resonance imaging (MRI) were reported in lumbar disc herniation [5]. There have been few reports on MRN findings in C5 or $\mathrm{C} 6$ radiculopathy. We report MRN and conventional MRI findings in four patients with C5 or C6 radiculopathy.

\section{CASE REPORT}

A summary of the findings in four patients is presented in Tables 1 and 2. Case 1 has been described in detail.

Figs. 1-4 illustrate brachial plexus MRN and cervical or shoulder MRI in each patient. Coronal T2 shorttau inversion recovery (STIR) image of brachial plexus MRN showed high signal intensity (HSI) or thickening of a single spinal nerve, which coincided with the level of herniated disc or stenosis in all four patients. T2-weighted image of shoulder MRI also revealed increased signal intensity or atrophy of shoulder girdle muscles in two patients who had symptoms over 4 weeks.

\section{Case 1}

A 40-year old male presented with a 6-week history of sudden-onset left shoulder girdle pain and intermittent radicular pain in the distal arm. At the onset, pain was too severe to allow rotation of the neck. Two weeks later, he noticed that he could not elevate his shoulder. At the first visit, pain severity was 5 according to the visual analog scale. There was atrophy of the left shoulder girdle muscles. Medical Research Council grade of the shoulder abductor, external rotator, and elbow flexor muscles was $2 / 5$. Sensory examination revealed abnormal sensation to light touch over the thumb area. The Spurling test was positive and radicular pain was relieved by shoulder abduction (Table 1).

Electrodiagnostic testing was performed at 6 weeks after the onset of pain. The sensory nerve conduction studies (NCSs) were normal. Motor NCSs of the suprascapular nerve and the axillary nerve showed markedly reduced amplitude in comparison with the unaffected side. Needle electromyography revealed abnormal spon-

Table 1. Summary of the clinical information

\begin{tabular}{|c|c|c|c|c|}
\hline & Case 1 & Case 2 & Case 3 & Case 4 \\
\hline Sex/age (yr) & $\mathrm{M} / 40$ & $\mathrm{M} / 50$ & $\mathrm{M} / 84$ & $\mathrm{M} / 45$ \\
\hline Cause & C5-6 herniated disc & C4-5 herniated disc & $\begin{array}{l}\text { C4-5 foraminal } \\
\text { stenosis }\end{array}$ & $\begin{array}{l}\text { C5-6 foraminal } \\
\text { stenosis }\end{array}$ \\
\hline Previous neck discomfort & - & - & + & + \\
\hline Symptoms duration & 6 weeks & 3 weeks & 6 months & 3 weeks \\
\hline Pain onset & Acute & Acute & Gradual & Gradual \\
\hline Pain location & $\begin{array}{l}\text { Interscapular area } \\
\text { and forearm }\end{array}$ & $\begin{array}{l}\text { Interscapular area } \\
\text { and shoulder girdle }\end{array}$ & Shoulder girdle & Deltoid area \\
\hline $\begin{array}{l}\text { Pain severity (VAS) at } \\
\text { nadir }\end{array}$ & 10 & 8 & 5 & 4 \\
\hline $\begin{array}{l}\text { Spurling test/ } \\
\text { shoulder abduction test }\end{array}$ & $+/+$ & $+/+$ & $+/+$ & $+/+$ \\
\hline Sensory loss & C6 dermatome & C5 dermatome & C5 dermatome & Absent \\
\hline Weakness (MRC grade) & $\begin{array}{l}\text { SAB (II), SER (II), } \\
\text { WE (IV) }\end{array}$ & $\begin{array}{l}\text { SAB (II), SER (II), } \\
\text { EF (II) }\end{array}$ & $\begin{array}{l}\text { SAB (II), SER (II), } \\
\text { EF (II) }\end{array}$ & SAB (III), SER (III) \\
\hline $\begin{array}{l}\text { Interval between pain } \\
\text { and weakness }\end{array}$ & 2 weeks & Parallel & Parallel & Parallel \\
\hline Atrophy & Obvious & Absent & Suspicious & Absent \\
\hline Treatment & ACDF & Conservative (ESI) & $\mathrm{ACDF}$ & $\begin{array}{l}\text { Conservative } \\
\text { (oral steroids) }\end{array}$ \\
\hline $\begin{array}{l}\text { Follow-up of weakness } \\
\text { at } 6 \text { months }\end{array}$ & $\begin{array}{l}\text { Marked improvement } \\
\text { after surgery }\end{array}$ & Near full recovery & $\begin{array}{l}\text { Marked improvement } \\
\text { after surgery }\end{array}$ & Near full recovery \\
\hline
\end{tabular}

VAS, visual analog scale; MRC, Medical Research Council; SAB, shoulder abductor; SER, shoulder external rotator; WE, wrist extensor; EF, elbow flexor; ESI, epidural steroid injection; ACDF, anterior cervical discectomy and fusion. 
Tae Gyu Seo, et al.

Table 2. Summary of the electrodiagnostic study, laboratory test, and imaging study results

\begin{tabular}{|c|c|c|c|c|}
\hline & Case 1 & Case 2 & Case 3 & Case 4 \\
\hline Anti-ganglioside antibody & Not available & Not available & Negative & Negative \\
\hline SNAP abnormalities & None & None & None & None \\
\hline CMAP decrease & $\begin{array}{l}\text { SSN (50\%), AN (90\%), } \\
\text { MCN (10\%) }\end{array}$ & $\begin{array}{l}\text { SSN (30\%), AN (55\%), } \\
\text { MCN (66\%) }\end{array}$ & $\begin{array}{l}\text { SSN (50\%), AN (82\%), } \\
\text { MCN (74\%) }\end{array}$ & $\begin{array}{l}\text { SSN (35\%), AN (48\%), } \\
\text { MCN (12\%) }\end{array}$ \\
\hline $\begin{array}{l}\text { Muscles showing } \\
\text { abnormal spontaneous } \\
\text { activity }\end{array}$ & SSP, ISP, BR, D, P & SSP, ISP, D, P & SSP, ISP, BB, D, P & $\mathrm{BB}, \mathrm{D}, \mathrm{P}$ \\
\hline $\begin{array}{l}\text { Suspected root } \\
\text { on spine MRI }\end{array}$ & C6 & C5 & $\mathrm{C} 5$ & $\mathrm{C} 6$ \\
\hline Involved root on MRN & C6 & $\mathrm{C} 5$ & $\mathrm{C} 5$ & C6 \\
\hline $\begin{array}{l}\text { Degenerative } \\
\text { foraminal stenosis }\end{array}$ & Absent & Absent & $\begin{array}{l}\text { Both } \mathrm{C} 4 / 5 \text { (most } \\
\text { severe), C5/6, C6/7 }\end{array}$ & Both C5/6 \\
\hline $\begin{array}{l}\text { Signal changes } \\
\text { in the shoulder muscles }\end{array}$ & SSP, ISP, D & None & SSP, ISP, D & None \\
\hline
\end{tabular}

SNAP, sensory nerve action potential; CMAP, compound muscle action potential; MRN, magnetic resonance neurography; SSN, suprascapular nerve; AN, axillary nerve; MCN, musculocutaneous nerve; SSP, supraspinatus; ISP, infraspinatus; BB, biceps brachii; BR, brachioradialis; D, deltoid; P, paraspinal muscle.
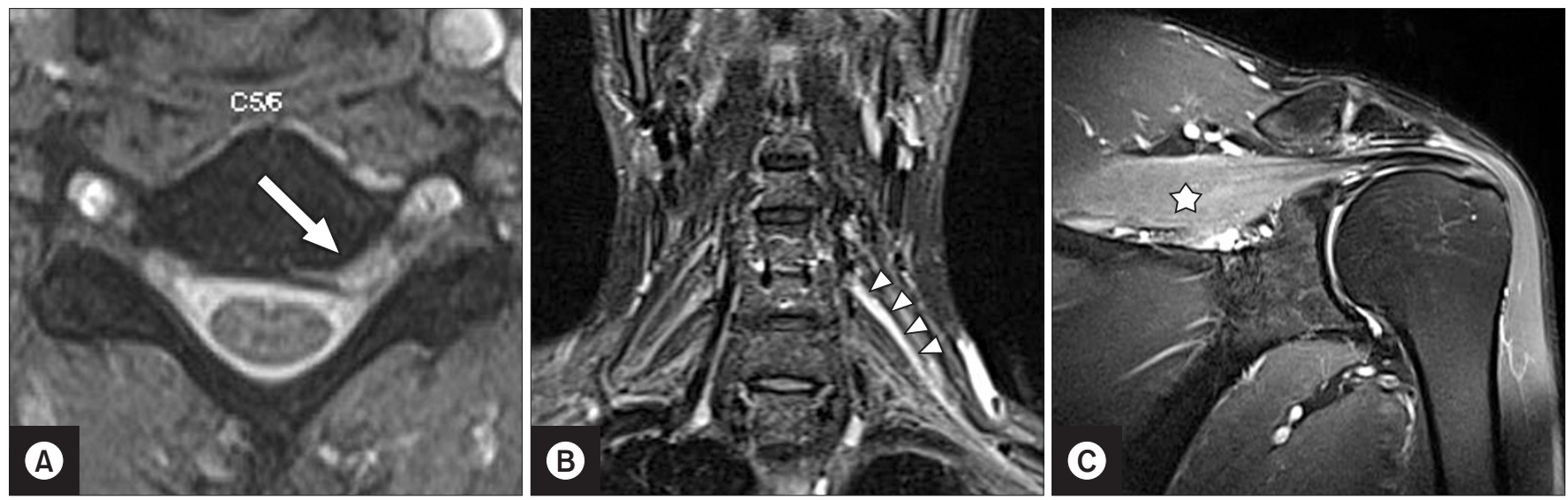

Fig. 1. Images of case 1. (A) C5-6 intervertebral disc herniation (arrow) compressing the left C6 root. (B) High signal intensity (HSI) in the C6 root (arrowheads) on coronal T2 short-tau inversion recovery (STIR) image. (C) HSI in the supraspinatus (asterisk) on coronal T2 STIR image.

taneous activity in the supraspinatus, infraspinatus, brachioradialis, deltoid, and C6 paraspinal muscle. The presence of anti-ganglioside antibody was not assessed (Table 2).

Cervical spine MRI and brachial plexus MRN were performed using a 1.5-T scanner (Avanto; Siemens, Erlangen, Germany). Cervical spine MRI showed herniation of the C5-6 intervertebral disc compressing the C6 root. Coronal T2 weighted STIR image (TR, 3800 ms; TE, 206 $\mathrm{ms}$ ) of brachial plexus MRN demonstrated HSI in the C6 spinal nerve. T2 weighted STIR image (TR, $4030 \mathrm{~ms}$; TE, $35 \mathrm{~ms}$ ) of shoulder MRI revealed HSI in the supraspinatus, infraspinatus, and deltoid (Table 2, Fig. 1).

A diagnosis of C6 radiculopathy due to C5-6 herniated disc was made according to the clinical manifestations, physical examination, electrodiagnostic testing, and imaging study. He received surgical treatment with C5-6 anterior cervical discectomy and fusion (ACDF). Six months after surgery, pain had completely subsided and weakness had improved. 

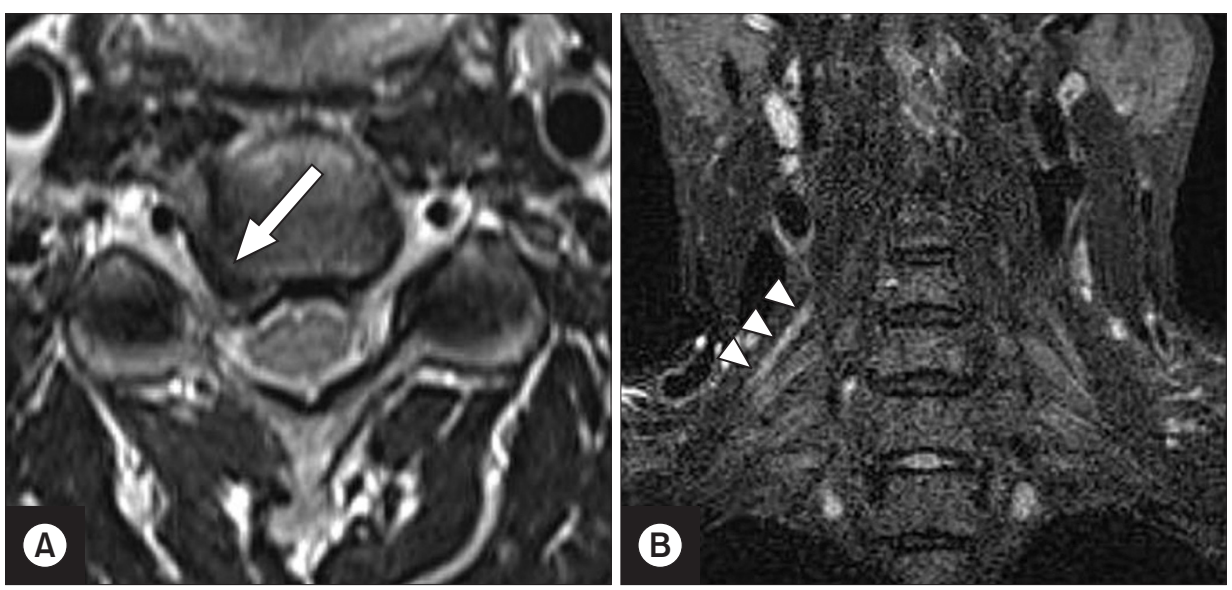

Fig. 2. Images of case 2. (A) C4-5 intervertebral disc herniation (arrow) compressing the right $\mathrm{C} 5$ root. (B) High signal intensity in the $\mathrm{C} 5$ root (arrowheads) on coronal T2 short-tau inversion recovery image.
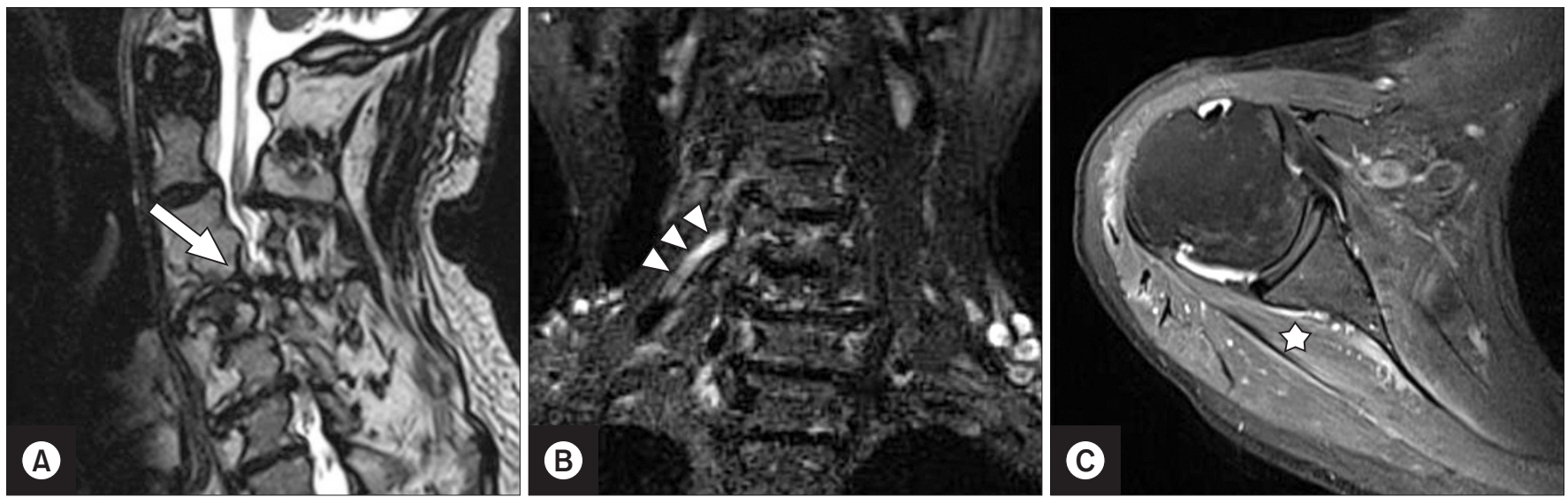

Fig. 3. Images of case 3. (A) Right C4-5 foraminal stenosis (arrow) compressing the C5 root. (B) High signal intensity (HSI) in the C5 root (arrowheads) on coronal T2 short-tau inversion recovery image. (C) HSI in the infraspinatus (asterisk) on axial T2-weighed image.
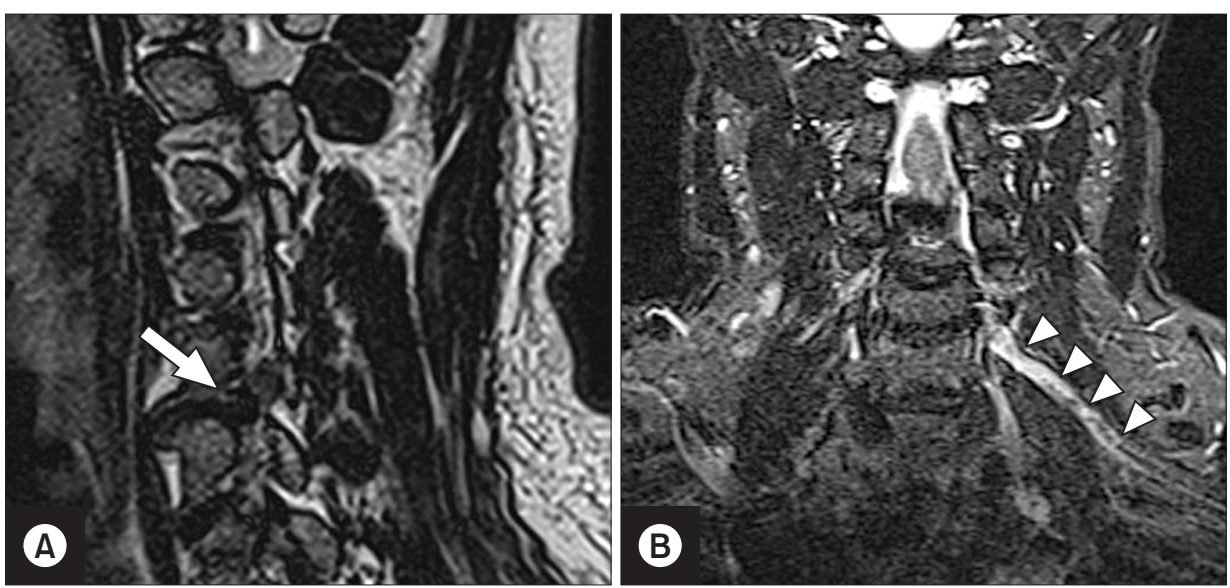

Fig. 4. Images of case 4. (A) Left C5-6 foraminal stenosis (arrow) compressing the $\mathrm{C} 6$ root. (B) Thickening of the C6 root (arrowheads) on coronal T2 short-tau inversion recovery image.

\section{DISCUSSION}

We made a diagnosis of CR in the four cases on the basis of history taking, physical examination, cervical MRI, and electrodiagnostic testing. Although only clinical presentations are not sufficient to distinguish CR from INA, CR 
typically presents with neck posture-dependent radiating pain and multiple provocation maneuvers (Spurling test, shoulder abduction test, and upper limb tension test) are more reliable in providing an accurate diagnosis of CR [1]. The characteristics of pain in INA are acute, very severe (numeric rating scale $>7$ ) and anything that the patient had not experienced before [6]. If not, one should consider alternative diagnosis rather than INA [6]. All patients had a positive Spurling sign and relief of radicular pain with shoulder abduction although their symptoms lasted for 3 weeks, suggesting mechanical compression of cervical roots. Cases 1 and 2 had obvious herniation of intervertebral discs. Dramatic improvement after C5-6 ACDF in case 1 favored the diagnosis of $\mathrm{C} 6$ radiculopathy rather than INA. Gradual onset, pain severity and improvement after surgery in case 3 also favored the diagnosis of C5 radiculopathy. Prominent stenosis at the concordant level, pain severity and the absence of abrupt-onset pain suggested the diagnosis of CR in case 4. All patients had abnormal spontaneous activity in the paraspinal muscle, which also suggested the diagnosis of CR.

When the physician encounters a patient with suddenonset severe shoulder pain and subsequent wasting of shoulder girdle muscles, the diagnosis becomes challenging. Although INA is a very discrete entity, the diagnosis of INA should be made when explainable lesions are ruled out [2]. It is sometimes impossible to distinguish INA from CR, especially if the patient has multilevel cervical spondylosis. However, early differential diagnosis of the two diseases is important because both delayed decompression in compressive $\mathrm{C} 5$ radiculopathy and unnecessary surgery for INA should be avoided.

Previous studies have demonstrated that HSI or thickening of the brachial plexus and edematous or atrophic change in shoulder girdle muscles were observed on brachial plexus MRN and conventional shoulder MRI of patients with INA $[3,4,7,8]$. The diagnosis of INA is suggested when there is an abnormality of shoulder girdle muscles and other causes such as trauma, excessive overhead activity, myopathy, myositis and tumor can be excluded [7]. However, our results suggest that abnormal signal intensity in the affected muscles might not be specific to INA and it only reflects the denervation process. Denervation in CR may cause an abnormal signal change on conventional MRI. Previous studies have revealed that in patients with acute or subacute INA, the brachial plexus was thickened and hyperintense on MRN $[3,4]$. However, our cases suggest that these findings do not guarantee the diagnosis of INA. We emphasize that both brachial plexus MRN and shoulder MRI should be taken with the consideration of clinical history, physical examination, and electrodiagnostic testing.

Park et al. [4] reported that three of four patients with INA had HSI in both C5 and C6 roots and one patient had HSI only in the C5 root. All our patients with C5 or C6 radiculopathy had HSI in only a single spinal nerve, which coincided with the level of herniated disc or stenosis. Further larger studies are needed to clarify whether the number of involved roots can distinguish CR from INA. We infer the clinical usefulness of brachial plexus MRN in CR based on case 3. In this patient, who had multilevel foraminal stenosis, determination of the affected level was difficult. In case 3, we detected HSI only in the C5 root and spinal nerve. Pain and weakness markedly improved after single-level decompression. Brachial plexus MRN might also be helpful in the management of multilevel cervical spondylosis.

We reported four patients with C5 or C6 radiculopathy who had definite weakness of shoulder girdle muscles. Our cases may not be typical because $\mathrm{C} 5$ or $\mathrm{C} 6$ radiculopathy without definite weakness is more common. Further investigation is needed to assess whether patients with relatively mild weakness or no weakness have similar patterns on brachial plexus MRN.

In conclusion, signal abnormality in the brachial plexus and shoulder girdle muscles on MR can be present in C5 or $\mathrm{C} 6$ radiculopathy. One should be careful about putting too much emphasis on brachial plexus MRN and shoulder MRI in the diagnosis of shoulder girdle pain and subsequent weakness. Brachial plexus MRN may be clinically useful for determination of the decompression level in patients with mutilevel foraminal stenosis.

\section{CONFLICT OF INTEREST}

No potential conflict of interest relevant to this article was reported.

\section{ACKNOWLEDGMENTS}

The research was supported by the Bisa Research Grant of Keimyung University in 2012. 


\section{REFERENCES}

1. Woods BI, Hilibrand AS. Cervical radiculopathy: epidemiology, etiology, diagnosis, and treatment. J Spinal Disord Tech 2015;28:E251-9.

2. van Alfen N, van Engelen BG. The clinical spectrum of neuralgic amyotrophy in 246 cases. Brain 2006;129(Pt 2):438-50.

3. Duman I, Guvenc I, Kalyon TA. Neuralgic amyotrophy, diagnosed with magnetic resonance neurography in acute stage: a case report and review of the literature. Neurologist 2007;13:219-21.

4. Park MS, Kim DH, Sung DH. Magnetic resonance neurographic findings in classic idiopathic neuralgic amyotrophy in subacute stage: a report of four cases. Ann Rehabil Med 2014;38:286-91.

5. Lee YS, Choi ES, Song CJ. Symptomatic nerve root changes on contrast-enhanced MR imaging after surgery for lumbar disk herniation. AJNR Am J Neuroradiol 2009;30:1062-7.

6. van Alfen N. The neuralgic amyotrophy consultation. J Neurol 2007;254:695-704.

7. Gaskin CM, Helms CA. Parsonage-Turner syndrome: MR imaging findings and clinical information of 27 patients. Radiology 2006;240:501-7.

8. Scalf RE, Wenger DE, Frick MA, Mandrekar JN, Adkins MC. MRI findings of 26 patients with Parsonage-Turner syndrome. AJR Am J Roentgenol 2007;189:W39-44. 